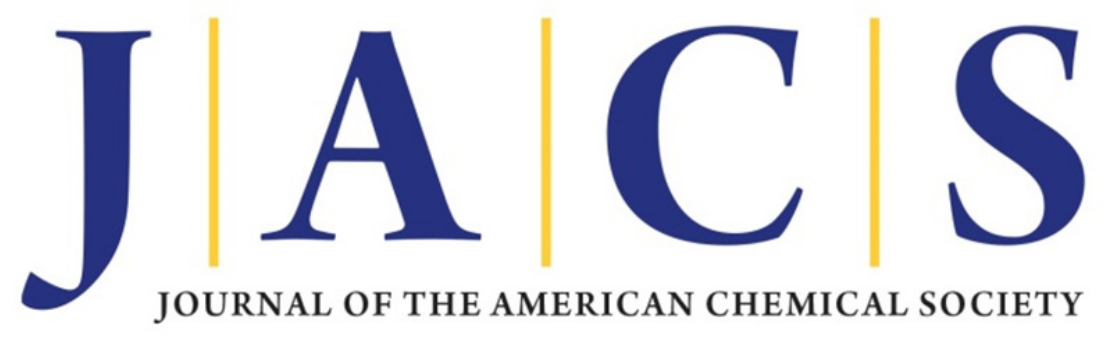

\title{
Cation-Dependent Gold Recovery with $\alpha$-Cyclodextrin Facilitated by Second-Sphere Coordination
}

Zhichang Liu, ${ }^{\dagger}$ Avik Samanta,${ }^{\dagger}$ Juying Lei, ${ }^{\dagger, \dagger}$ Junling Sun, ${ }^{\dagger}$ Yuping Wang, ${ }^{\dagger}$ and J. Fraser Stoddart* $*$

${ }^{\dagger}$ Department of Chemistry, Northwestern University, 2145 Sheridan Road, Evanston, Illinois 60208-3113, USA.

${ }^{\ddagger}$ School of Resources and Environmental Engineering, East China University of Science and Technology, 130 Meilong Road, Shanghai 200237, China.

*E-mail: stoddart@northwestern.edu

\section{Supporting Information}

Table of Contents

A. Materials and Methods....

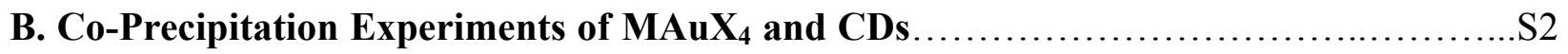

C. Characterization of the Co-Precipitates of $\alpha \cdot \mathrm{K} \bullet \mathrm{Br}, \boldsymbol{\alpha} \bullet \mathrm{Rb} \bullet \mathrm{Br}$, and $\boldsymbol{\alpha} \bullet \mathrm{Cs} \bullet \mathrm{Br} \ldots \ldots \ldots \ldots \ldots \mathrm{S} 3$

D. Single-Crystal X-Ray Crystallographic Analyses.............................. 44

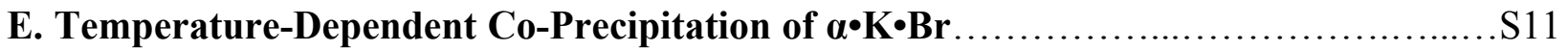

F. $\alpha$-CD Concentration-Dependent Co-Precipitation Experiments for $\boldsymbol{\alpha} \cdot \mathrm{K} \bullet \mathbf{B r} \ldots \ldots \ldots \ldots . \mathrm{S} 11$

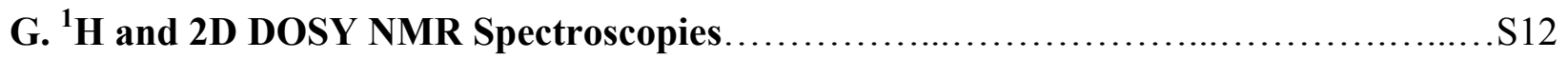

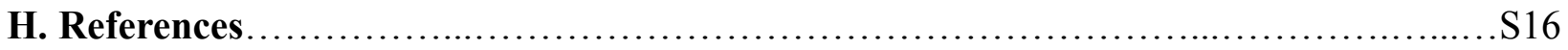




\section{A. Materials and Methods}

All reagents were purchased from Aldrich and used without further purification. High purity $\mathrm{H}_{2} \mathrm{O}$ was generated by a Milli-Q apparatus (Millipore). Proton nuclear magnetic resonance $\left({ }^{1} \mathrm{H}\right.$ NMR) as well as variable temperature ${ }^{1} \mathrm{H}$ and 2D DOSY NMR spectra were recorded on Bruker Avance 600 and 400 spectrometers, with working frequencies of 600 and $400 \mathrm{MHz}$ for ${ }^{1} \mathrm{H}$, respectively.

\section{B. Co-Precipitation Experiments of $\mathrm{MAuX}_{4}$ and CDs}

Aqueous stock solutions of $\mathrm{NaAuCl}_{4}, \mathrm{NaAuBr}_{4}, \mathrm{KAuCl}_{4}$, and $\mathrm{KAuBr}_{4}$ were prepared by dissolving the corresponding commercially available salts in $\mathrm{H}_{2} \mathrm{O}$, while aqueous solutions of $\mathrm{RbAuCl}_{4}, \mathrm{RbAuBr}_{4}, \mathrm{CsAuCl}_{4}$, and $\mathrm{CsAuBr}_{4}$ were prepared by neutralizing identical amounts of $\mathrm{HAuCl}_{4}$ or $\mathrm{HAuBr}_{4}$ with the corresponding base, namely $\mathrm{RbOH}$ or $\mathrm{CsOH}$ in $\mathrm{H}_{2} \mathrm{O}$. Powdered samples of $\alpha-, \beta-$, or $\gamma$-CD $\left(0.04\right.$ mmol, corresponding to the molar ratios of $1: 2$ for $\mathrm{KAuBr}_{4}$ to $\alpha-$ CD) were added directly into the aqueous solutions $(10 \mathrm{mM}, 2 \mathrm{~mL})$ of $\mathrm{MAuX}_{4}$, respectively. The resulting mixtures in $4 \mathrm{~mL}$ vials were thoroughly mixed. Co-precipitation occurred selectively in the case of the three mixtures of $\alpha-\mathrm{CD}$ with $\mathrm{KAuBr}_{4}, \mathrm{RbAuBr}_{4}$, and $\mathrm{CsAuBr}_{4}$. The coprecipitates were removed by filtration, and the co-precipitation yields were obtained indirectly by analyzing the concentrations of $\left[\mathrm{AuBr}_{4}\right]^{-}$remaining in the filtrates by UV-Vis spectrophotometry employing the absorbance of $\left[\mathrm{AuBr}_{4}\right]^{-}$at $\lambda_{\max }=\sim 380 \mathrm{~nm}$. The intensity of the UV-Vis absorption band correlates (Figure S1) linearly with the concentration of [AuBr $]^{-}$over a range of concentrations from 0.387 to $1.165 \mathrm{mM}$ in $\mathrm{H}_{2} \mathrm{O}$ with $R^{2}=0.999$. 
a)

b)
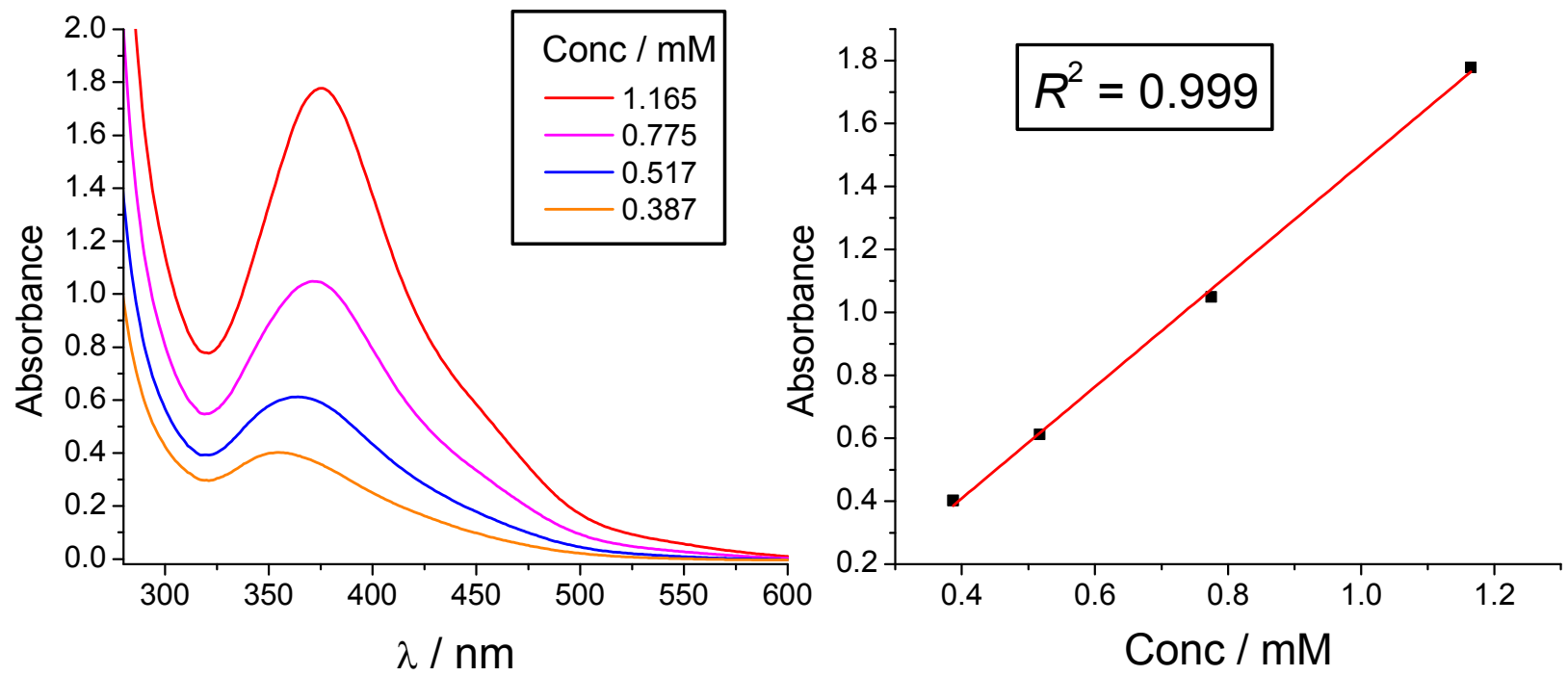

Figure S1. a) UV-Vis Spectra of the absorption band of $\left[\mathrm{AuBr}_{4}\right]^{-}$at $\lambda_{\max }=\sim 380 \mathrm{~nm}$ recorded over a range of concentrations from 0.387 to $1.165 \mathrm{mM}$ in $\mathrm{H}_{2} \mathrm{O}$. b) The intensity of the absorption band correlates linearly with the concentration of $\left[\mathrm{AuBr}_{4}\right]^{-}$with $R^{2}=0.999$.

\section{Characterization of the $\mathrm{Co}-\mathrm{Precipitates}$ of $\alpha \cdot \mathrm{K} \bullet \mathrm{Br}, \alpha \cdot \mathrm{Rb} \bullet \mathrm{Br}$, and $\alpha \cdot \mathrm{Cs} \bullet \mathrm{Br}$}

Scanning electron microscopy (SEM) samples were prepared by drop-casting the as-synthesized co-precipitates onto silicon wafers, followed by drying in air. SEM Images were obtained using a Hitachi SU-8030 FE-SEM. Powder X-ray diffraction (PXRD) data were collected on a Rigaku ATXG X-ray diffractometer using $\mathrm{Cu}-\mathrm{K}_{\alpha}$ radiation $(\lambda=1.54178 \AA, 50 \mathrm{kV}, 240 \mathrm{~mA})$ at room temperature. 


\section{Single-Crystal X-Ray Crystallographic Analyses}

Single crystals of 20 complexes - namely, $\alpha \cdot \mathbf{N a} \cdot \mathbf{C l}, \alpha \cdot \mathbf{K} \cdot \mathbf{C l}, \alpha \cdot \mathbf{R b} \cdot \mathbf{C l}, \alpha \cdot \mathbf{C s} \cdot \mathbf{C l}, \alpha \cdot \mathbf{N a} \cdot \mathbf{B r}$, $\alpha \cdot \mathrm{K} \bullet \mathrm{Br}, \alpha \cdot \mathrm{Rb} \bullet \mathrm{Br}, \alpha \cdot \mathrm{Cs} \bullet \mathrm{Br}, \beta \cdot \mathrm{Na} \bullet \mathrm{Cl}, \beta \cdot \mathrm{K} \bullet \mathrm{Cl}, \beta \cdot \mathrm{Rb} \bullet \mathrm{Cl}, \beta \bullet \mathrm{Na} \bullet \mathrm{Br}, \beta \bullet \mathrm{K} \bullet \mathrm{Br}, \beta \bullet \mathrm{Rb} \bullet \mathrm{Br}, \gamma \cdot \mathrm{Na} \bullet \mathrm{Cl}$, $\gamma \cdot \mathbf{K} \cdot \mathbf{C l}, \gamma \cdot \mathbf{R b} \cdot \mathbf{C l}, \gamma \cdot \mathbf{N a} \bullet \mathbf{B r}, \gamma \cdot \mathbf{K} \cdot \mathbf{B r}, \gamma \cdot \mathbf{R b} \cdot \mathbf{B r}$ - were grown by slow vapor diffusion of EtOH into aqueous solutions of 1:2 mixtures of $\mathrm{MAuX}_{4}$ and $\alpha-, \beta-$, or $\gamma$-CD. Crystals suitable for X-ray crystallography were selected and mounted using oil (Infineum V8512) on a glass fiber and transferred to the cold gas stream cooled by liquid $\mathrm{N}_{2}$. The X-ray crystal data were collected (Table S1 and Table S2) at $100 \mathrm{~K}$ using a Bruker Kappa APEX CCD area detector, equipped with a Cu-K $\mathrm{K}_{\alpha}$ microsource with MX optics. SADABS-2008/1 (Bruker, 2008) was used for absorption correction. The structures were solved by direct methods and refined subsequently using the Bruker SHELXTL software package. ${ }^{\mathrm{S} 1}$ The majority of the hydrogen atoms were assigned riding isotropic displacement parameters and constrained to idealized geometries. Crystallographic images were produced using UCSF Chimera 1.10.2. ${ }^{\mathrm{S} 2}$ Distances and angles were measured employing Mercury 3.8. Figures S2-S5 show the single-crystal packing superstructures of $\alpha \cdot \mathbf{N a} \cdot \mathbf{C l}, \alpha \cdot \mathbf{K} \cdot \mathbf{C l}, \alpha \cdot \mathbf{R b} \cdot \mathbf{C l}$, and $\alpha \cdot C s \cdot \mathbf{C l}$. Table S1 and Table S2 report the crystallographic data of twelve $\beta$ - and $\gamma$-CD complexes-namely, $\boldsymbol{\beta} \cdot \mathbf{N a} \cdot \mathbf{C l}, \boldsymbol{\beta} \cdot \mathbf{K} \cdot \mathbf{C l}, \boldsymbol{\beta} \cdot \mathbf{R b} \cdot \mathbf{C l}$, $\beta \bullet \mathrm{Na} \bullet \mathrm{Br}, \beta \bullet \mathrm{K} \bullet \mathrm{Br}, \beta \cdot \mathrm{Rb} \bullet \mathrm{Br}, \gamma \cdot \mathrm{Na} \cdot \mathrm{Cl}, \gamma \cdot \mathrm{K} \bullet \mathrm{Cl}, \gamma \cdot \mathrm{Rb} \bullet \mathrm{Cl}, \gamma \cdot \mathrm{Na} \bullet \mathrm{Br}, \gamma \cdot \mathrm{K} \bullet \mathrm{Br}$, and $\gamma \cdot \mathrm{Rb} \bullet \mathrm{Br}$. CCDC 1479836-1479849 and 918412-918417 contain the Supplementary Crystallographic Data for this article. These data can be obtained free of charge from the Cambridge Crystallographic Data Centre via www.ccdc.cam.ac.uk/data_request/cif. 
Table S1. Crystallographic Data for Six Complexes Between $\beta-C D$ and $\operatorname{MAuX}_{4}(\mathrm{M}=\mathrm{Na} / \mathrm{K}$ / Rb, $\mathbf{X}=\mathbf{C l} / \mathbf{B r})$

\begin{tabular}{|c|c|c|c|c|c|c|}
\hline Complex & $\beta \cdot \mathbf{N a} \cdot \mathbf{B r}$ & $\beta \cdot \mathbf{K} \bullet \mathbf{B r}$ & $\beta \bullet \mathbf{R b} \cdot \mathbf{B r}$ & $\beta \cdot \mathbf{N a} \cdot \mathbf{C l}$ & $\beta \cdot \mathbf{K} \cdot \mathbf{C l}$ & $\beta \cdot \mathbf{R b} \cdot \mathbf{C l}$ \\
\hline $\mathrm{CD}: \mathrm{MAuX}_{4}$ & $2: 1$ & $2: 1$ & $2: 1$ & $2: 1$ & $2: 1$ & $2: 1$ \\
\hline$T / \mathrm{K}$ & 99.99 & $109(2)$ & 99.95 & $100(2)$ & $100(2)$ & $100(2)$ \\
\hline Crystal System & Monoclinic & Monoclinic & Monoclinic & Monoclinic & Monoclinic & Monoclinic \\
\hline Space Group & $P 2_{1}$ & $P 2_{1}$ & $P 2_{1}$ & $P 2_{1}$ & $P 2_{1}$ & $P 2_{1}$ \\
\hline$a / \AA$ & $15.8355(5)$ & $15.8246(4)$ & $15.8404(4)$ & $15.7324(9)$ & $15.7337(3)$ & $15.7207(10)$ \\
\hline$b / \AA$ & 24.4404(7) & $24.5009(6)$ & $24.5602(6)$ & $24.3405(13)$ & $24.3445(5)$ & $24.4010(16)$ \\
\hline$c / \AA$ & $19.0125(6)$ & $19.0924(5)$ & $19.0823(6)$ & $19.2739(12)$ & $19.2645(4)$ & 19.1401(13) \\
\hline$\alpha /^{\circ}$ & 90 & 90 & 90 & 90 & 90 & 90 \\
\hline$\beta /{ }^{\circ}$ & $108.424(10)$ & 108.401(10) & $108.399(2)$ & $108.952(3)$ & $108.748(1)$ & $108.670(3)$ \\
\hline$\gamma /{ }^{\circ}$ & 90 & 90 & 90 & 90 & 90 & 90 \\
\hline$V / \AA^{3}$ & $6981.2(4)$ & $7024.0(3)$ & $7044.3(3)$ & $6980.5(7)$ & $6987.3(2)$ & $6955.8(8)$ \\
\hline$Z$ & 2 & 2 & 2 & 2 & 2 & 2 \\
\hline$\rho_{\text {calcd }}\left[\mathrm{g} \mathrm{cm}^{-3}\right]$ & 1.402 & 1.353 & 1.392 & 1.269 & 1.392 & 1.338 \\
\hline$\mu\left[\mathrm{mm}^{-1}\right]$ & 2.298 & 4.357 & 3.763 & 3.013 & 3.392 & 3.951 \\
\hline$F(000)$ & 3016 & 2922 & 3045 & 2781 & 3024 & 2896 \\
\hline Goodness-of-fit on & 0.988 & 1.032 & 1.064 & 1.020 & 1.058 & 1.047 \\
\hline \multicolumn{7}{|l|}{$F^{2}$} \\
\hline$R_{1}[\mathrm{I}>2 \sigma(\mathrm{I})]$ & 0.0549 & 0.08 & 0.069 & 0.0469 & 0.0618 & 0.0810 \\
\hline$w R_{2}$ [all data] & 0.1501 & 0.2225 & 0.1938 & 0.1284 & 0.1630 & 0.2247 \\
\hline CCDC No. & 1479841 & 918414 & 1479844 & 1479843 & 918415 & 1479845 \\
\hline
\end{tabular}


Table S2. Crystallographic Data for Six Complexes Between $\gamma-\mathrm{CD}$ and $\mathrm{MAuX} \mathrm{X}_{4}(\mathrm{M}=\mathrm{Na} /$ $\mathrm{K} / \mathbf{R b}, \mathbf{X}=\mathbf{C l} / \mathbf{B r})$

\begin{tabular}{|c|c|c|c|c|c|c|}
\hline Complex & $\gamma \cdot \mathrm{Na} \cdot \mathrm{Br}$ & $\gamma \bullet \mathbf{K} \cdot \mathbf{B r}$ & $\gamma \cdot \mathbf{R b} \cdot \mathbf{B r}$ & $\gamma \cdot \mathrm{Na} \cdot \mathrm{Cl}$ & $\gamma \bullet \mathbf{K} \bullet \mathbf{C l}$ & $\gamma \cdot \mathbf{R b} \cdot \mathrm{Cl}$ \\
\hline $\mathrm{CD}: \mathrm{MAuX}_{4}$ & $3: 1$ & $3: 1$ & $3: 1$ & $3: 1$ & $3: 1$ & $3: 1$ \\
\hline$T / \mathrm{K}$ & 99.97 & $100(2)$ & 99.95 & $100(2)$ & $100(2)$ & 99.96 \\
\hline Crystal System & Tetragonal & Tetragonal & Tetragonal & Tetragonal & Tetragonal & Tetragonal \\
\hline Space Group & $P 42_{1} 2$ & $P 42_{1} 2$ & $P 42_{1} 2$ & $P 42_{1} 2$ & $P 42_{1} 2$ & $P 42_{1} 2$ \\
\hline$a / \AA$ & $23.6486(4)$ & $23.6711(11)$ & $23.7386(6)$ & $23.761(12)$ & $23.6973(3)$ & $23.7355(11)$ \\
\hline$b / \AA$ & $23.6486(4)$ & 23.6711(11) & $23.7386(6)$ & $23.761(12)$ & $23.6973(3)$ & $23.7355(11)$ \\
\hline$c / \AA$ & $22.7925(5)$ & $22.7697(14)$ & $22.7883(6)$ & $22.836(17)$ & $22.8929(4)$ & $22.8031(11)$ \\
\hline$\alpha /^{\circ}$ & 90 & 90 & 90 & 90 & 90 & 90 \\
\hline$\beta /{ }^{\circ}$ & 90 & 90 & 90 & 90 & 90 & 90 \\
\hline$\gamma /{ }^{\circ}$ & 90 & 90 & 90 & 90 & 90 & 90 \\
\hline$V / \AA^{3}$ & $12746.9(5)$ & $12758.3(10)$ & $12841.7(7)$ & $12893(16)$ & $12855.8(3)$ & $12846.7(13)$ \\
\hline$Z$ & 2 & 2 & 1 & 1 & 2 & 1 \\
\hline$\rho_{\text {calcd }}\left[\mathrm{g} \mathrm{cm}^{-3}\right]$ & 1.223 & 1.122 & 1.113 & 1.051 & 1.093 & 1.108 \\
\hline$\mu\left[\mathrm{mm}^{-1}\right]$ & 2.658 & 0.977 & 1.910 & 0.394 & 2.200 & 1.755 \\
\hline$F(000)$ & 4876 & 4490 & 4493 & 4294 & 4422 & 4501 \\
\hline Goodness-of-fit on $F^{2}$ & 0.937 & 0.836 & 1.009 & 1.043 & 1.061 & 1.047 \\
\hline$R_{1}[\mathrm{I}>2 \sigma(\mathrm{I})]$ & 0.0548 & 0.0779 & 0.0758 & 0.0810 & 0.0542 & 0.0716 \\
\hline$w R_{2}$ [all data] & 0.1542 & 0.2255 & 0.2172 & 0.2521 & 0.1696 & 0.2184 \\
\hline CCDC No. & 1479842 & 918416 & 1479848 & 1479847 & 918417 & 1479846 \\
\hline
\end{tabular}


a)
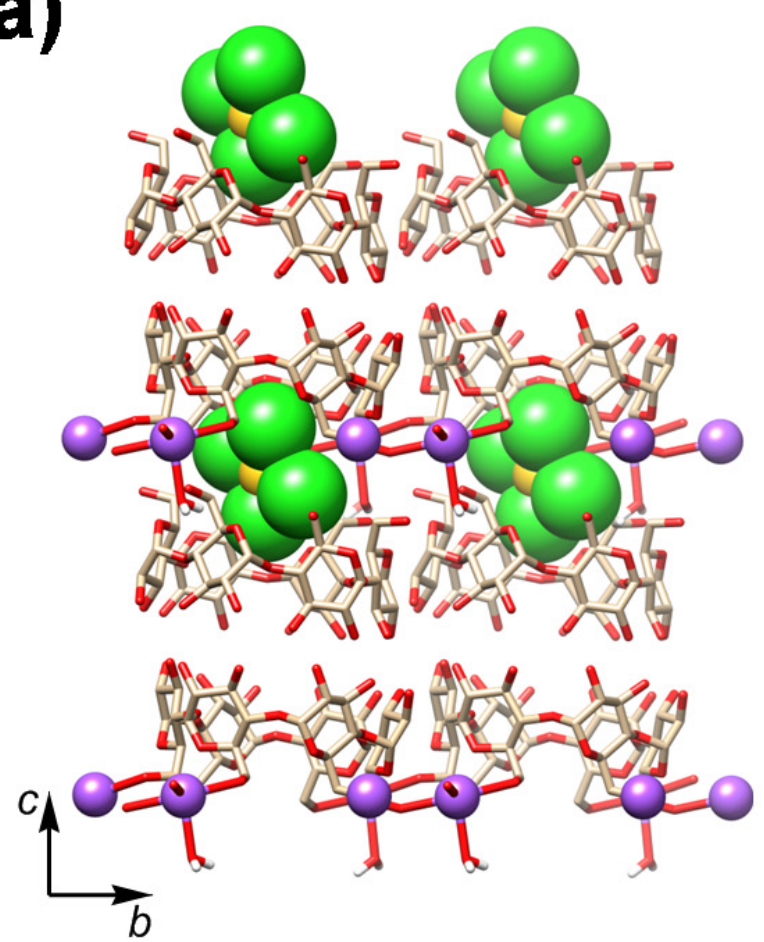

b)
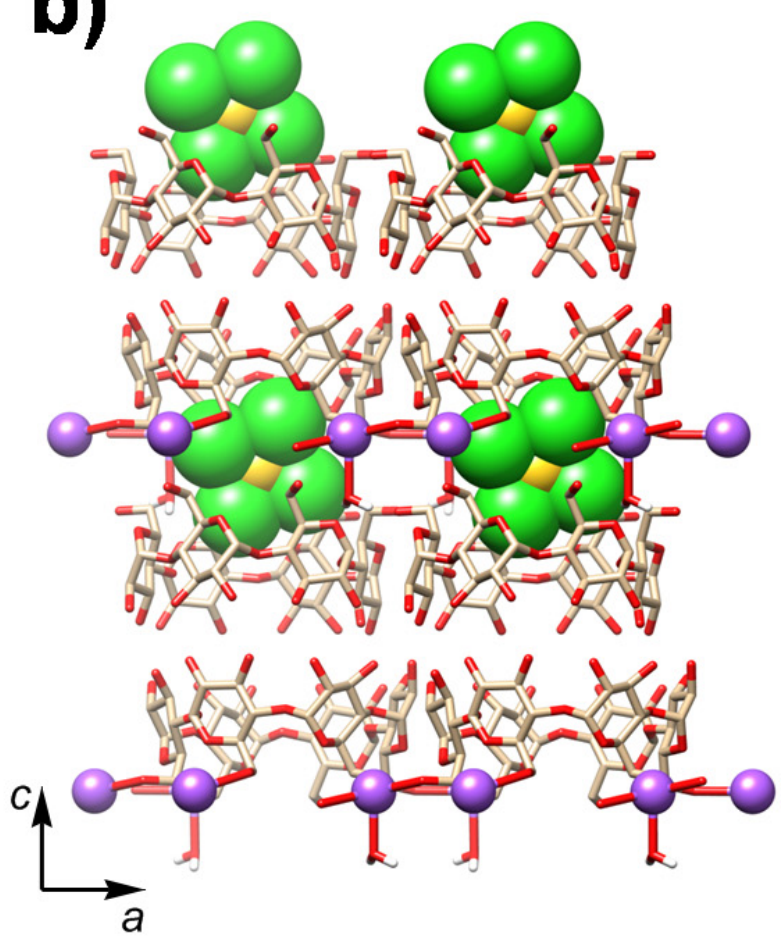

c)
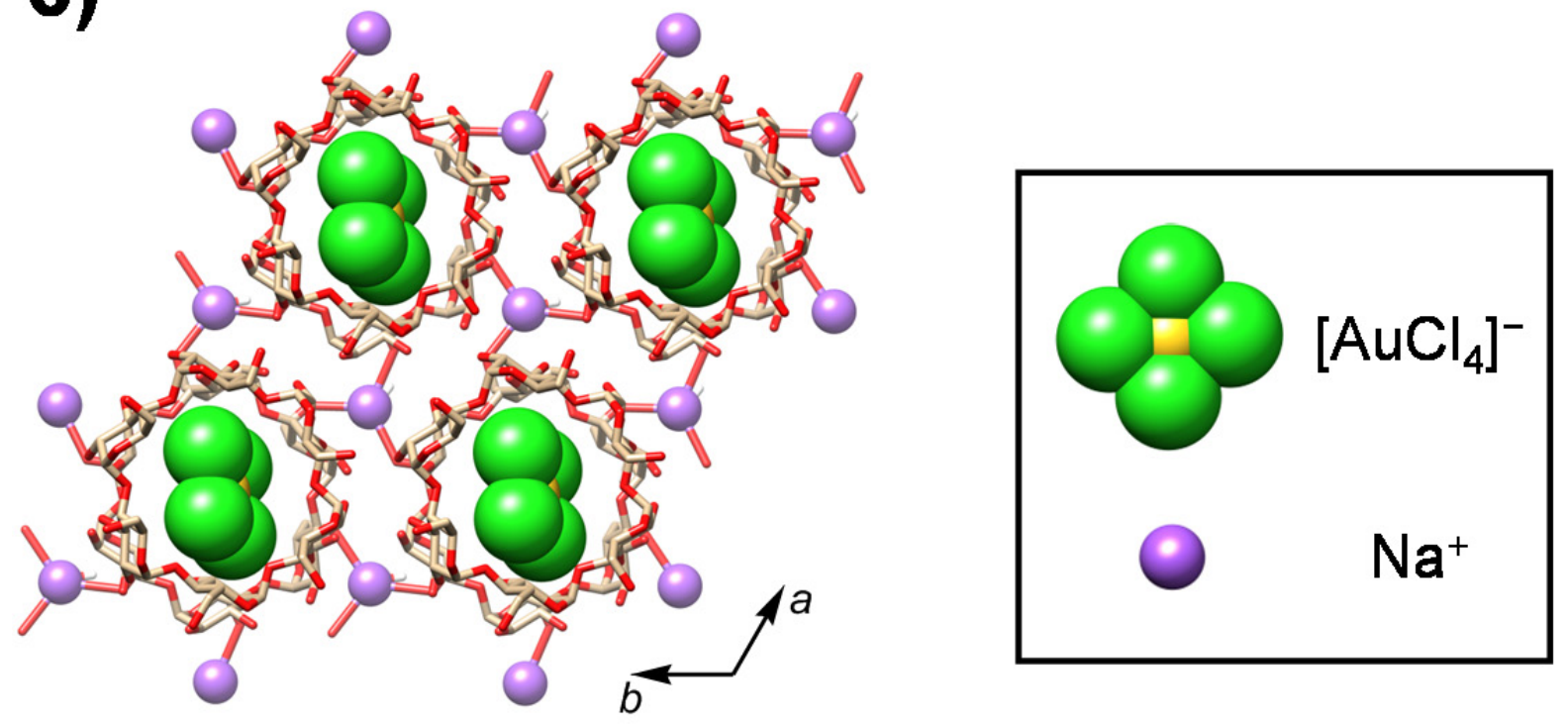

Figure S2. Three views of the single-crystal X-ray superstructure of complex $\boldsymbol{\alpha} \bullet \mathbf{N a} \cdot \mathbf{C l}$. C, tan; $\mathrm{O}$, red; $\mathrm{Cl}$, green; Au, yellow; Na, purple. 
a)

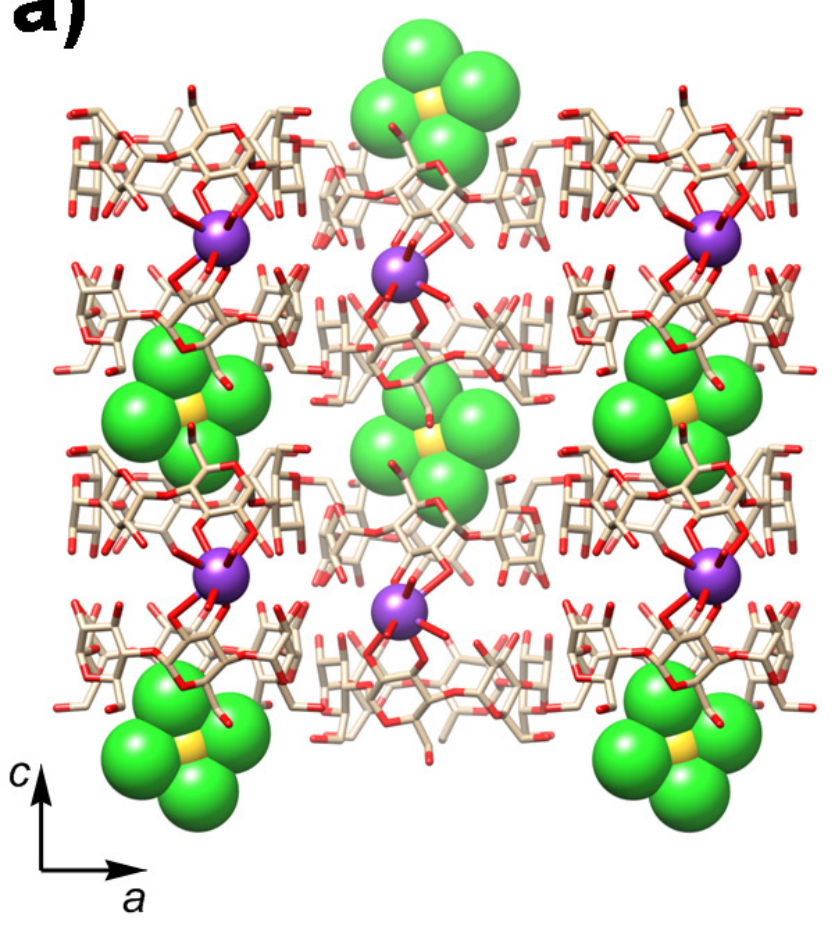

c)

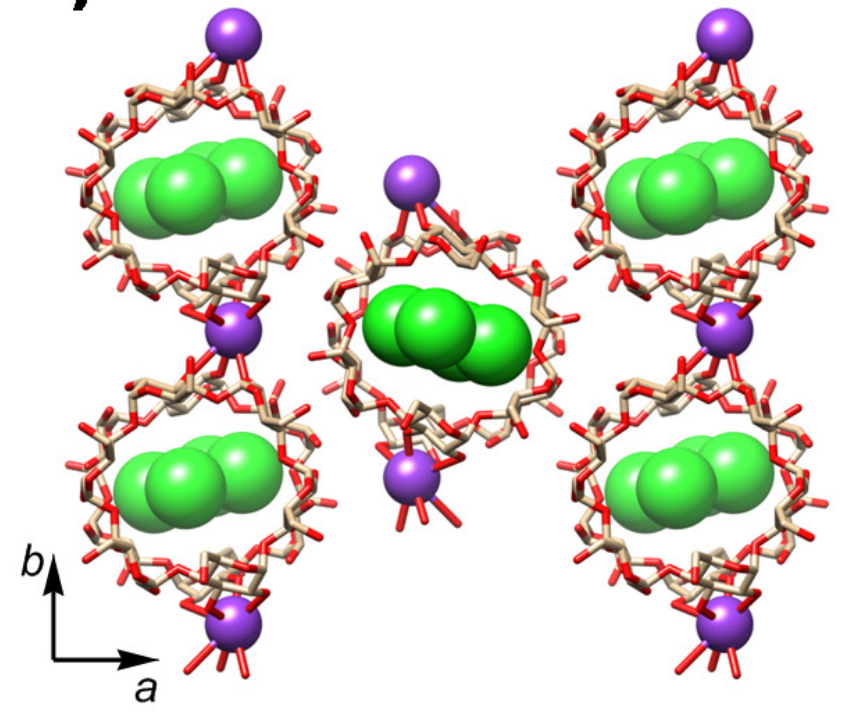

b)

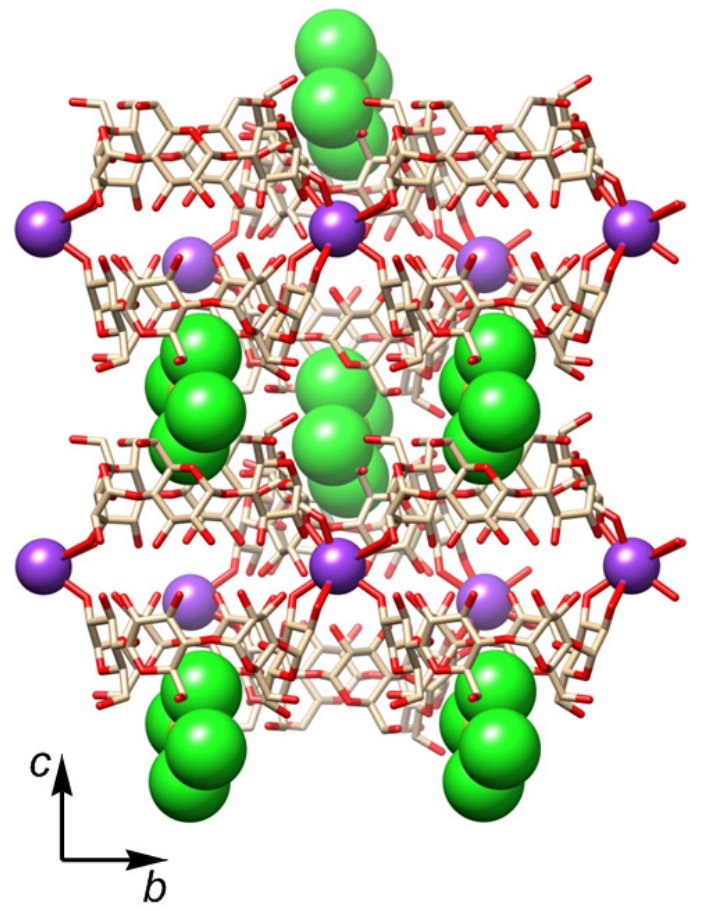

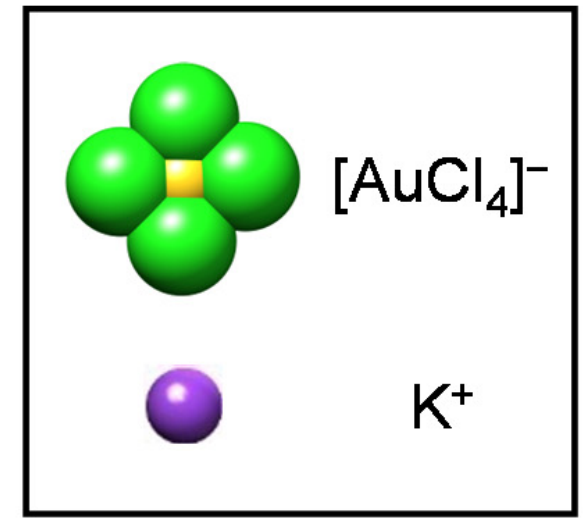

Figure S3. Three views of the single-crystal X-ray superstructure of complex $\boldsymbol{\alpha} \cdot \mathbf{K} \bullet \mathbf{C l}$. C, tan; O, red; $\mathrm{Cl}$, green; Au, yellow; K, purple. 
a)

b)
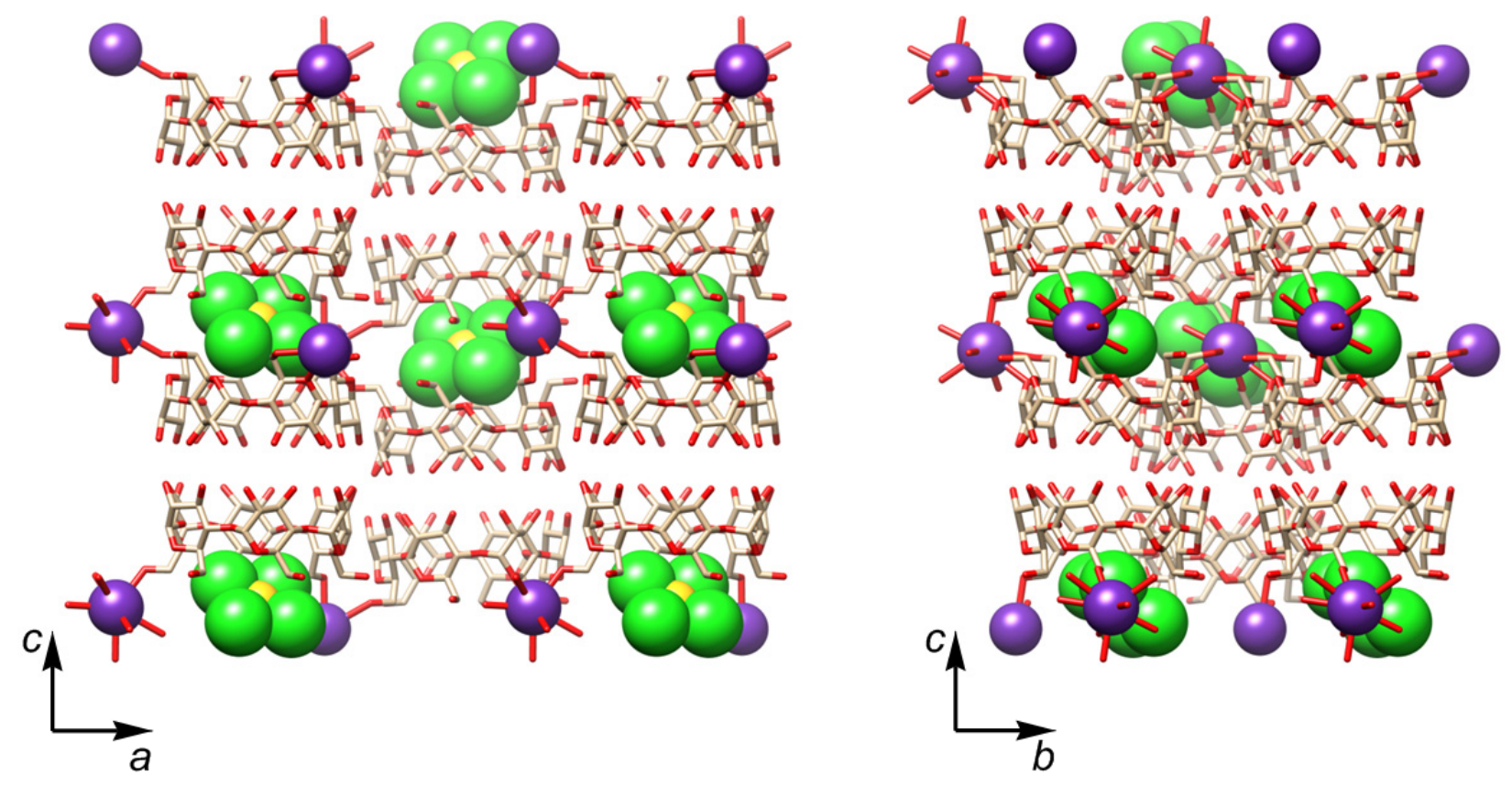

c)
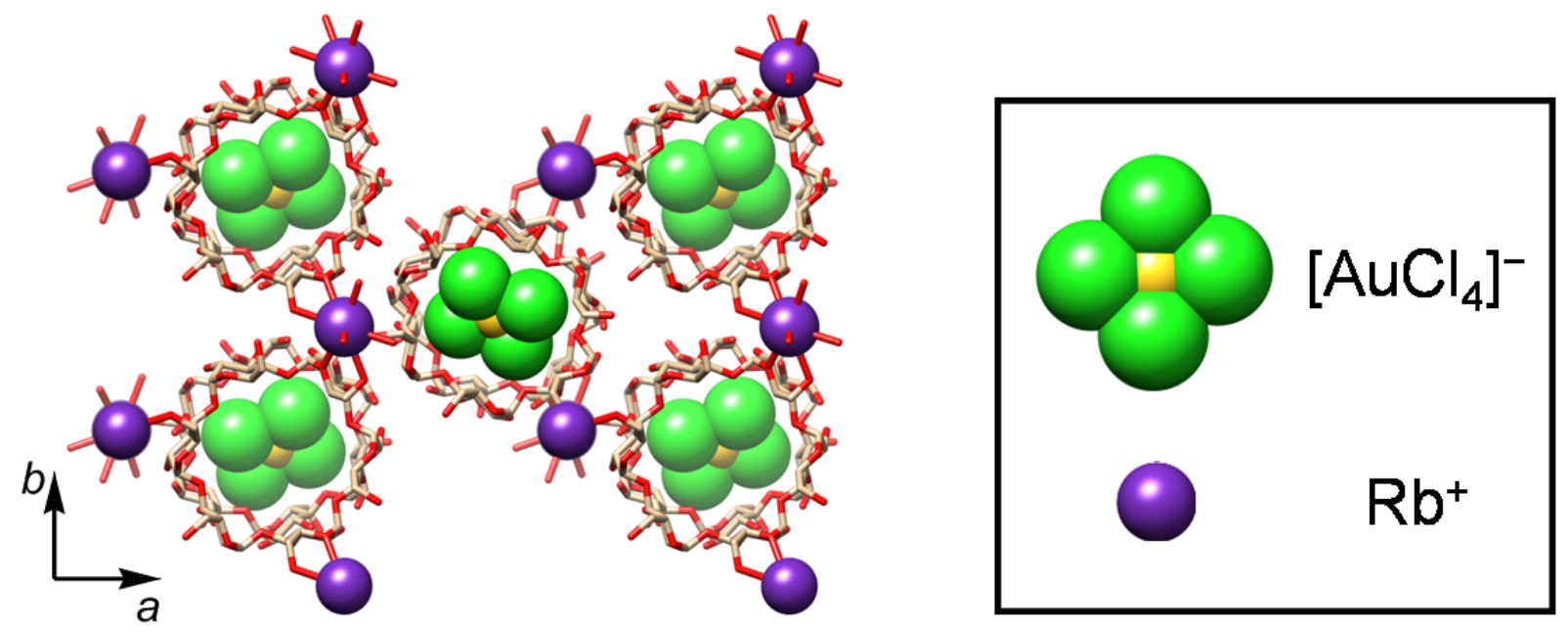

Figure S4. Three views of the single-crystal X-ray superstructure of complex $\boldsymbol{\alpha} \cdot \mathbf{R b} \cdot \mathbf{C l}$. C, tan; $\mathrm{O}$, red; $\mathrm{Cl}$, green; $\mathrm{Au}$, yellow; $\mathrm{Rb}$, purple. 
a)

b)
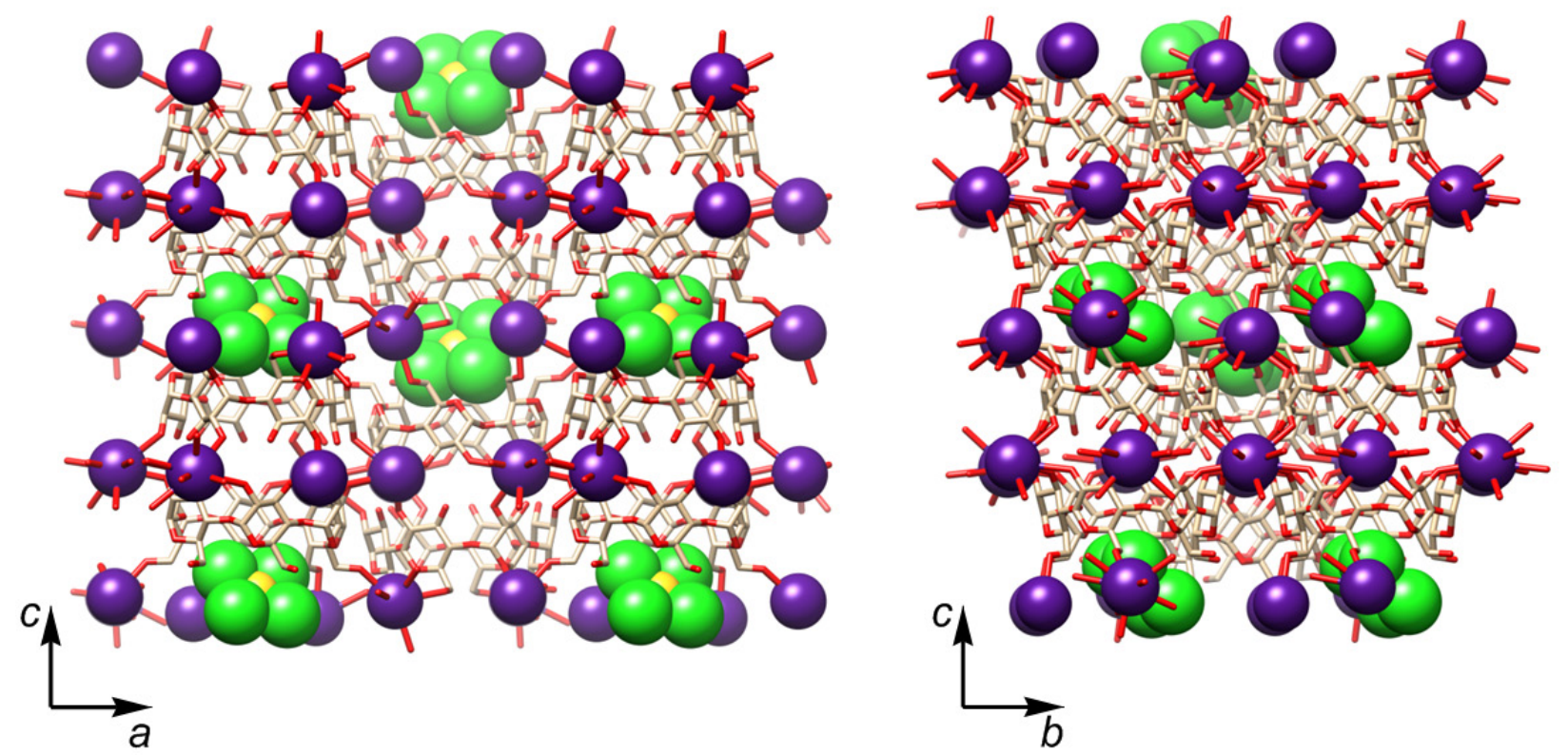

c)
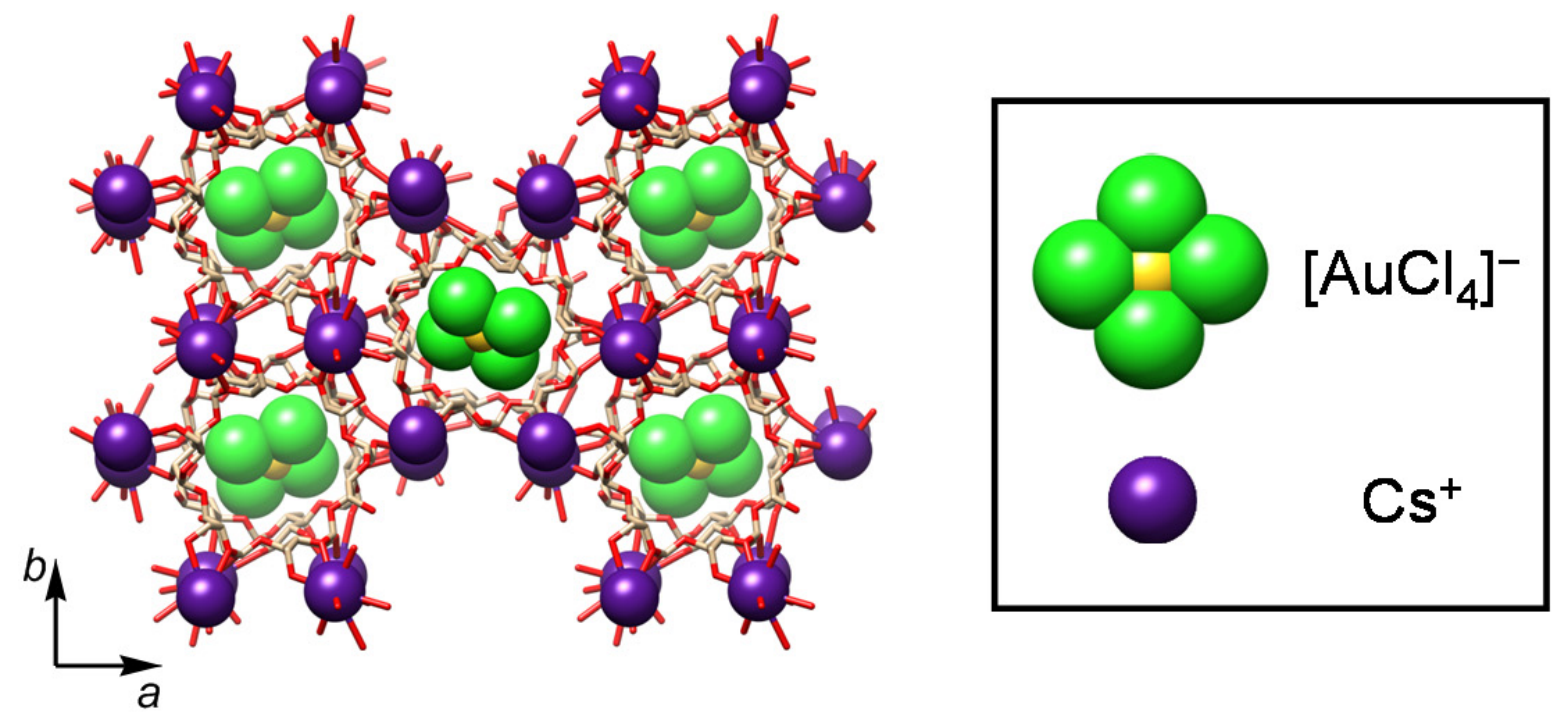

Figure S5. Three views of the single-crystal X-ray superstructure of complex $\boldsymbol{\alpha} \bullet \mathbf{C s} \cdot \mathbf{C l}$. C, tan; O, red; Cl, green; Au, yellow; Cs, purple. 


\section{E. Temperature-Dependent Co-Precipitation of $\alpha \cdot \mathrm{K} \cdot \mathrm{Br}$}

Five aqueous solutions of $\mathrm{KAuBr}_{4}(10 \mathrm{mM})$ were prepared by dissolving $\mathrm{KAuBr}_{4}(0.02 \mathrm{mmol}$, $11.1 \mathrm{mg})$ in $\mathrm{H}_{2} \mathrm{O}(2 \mathrm{~mL}) . \alpha-\mathrm{CD}(0.04 \mathrm{mmol}, 38.9 \mathrm{mg})$ was added as a powder into this aqueous solution of $\mathrm{KAuBr}_{4}$. The five resulting mixtures were fully mixed in $4 \mathrm{~mL}$ vials. The mixtures became clear for about $1 \mathrm{~min}$ and then gradually turned milky. These mixtures were then immersed into $\mathrm{H}_{2} \mathrm{O}$ baths at five precisely preset temperatures $\left(0,4,10,15,20^{\circ} \mathrm{C}\right)$ for $10 \mathrm{~h}$. The mixtures, which consisted of pale-brown suspensions, were filtered rapidly with a Buchner funnel under vacuum. The co-precipitation yields and solubilities of $\boldsymbol{\alpha} \cdot \mathbf{K} \cdot \mathbf{B r}$ at different temperatures were obtained indirectly by analyzing the concentrations of $\left[\mathrm{AuBr}_{4}\right]^{-}$ions remaining in the filtrates with UV-Vis spectrophotometry based on the absorbance of $\left[\mathrm{AuBr}_{4}\right]^{-}$at $\lambda_{\max }=\sim 380 \mathrm{~nm}$.

\section{F. $\alpha-C D$ Concentration-Dependent Co-Precipitation Experiments for $\alpha \cdot \mathrm{K} \bullet \mathrm{Br}$}

Five aqueous solutions of $\mathrm{KAuBr}_{4}(10 \mathrm{mM})$ were prepared by dissolving $\mathrm{KAuBr}_{4}(0.02 \mathrm{mmol}$, $11.1 \mathrm{mg})$ in $\mathrm{H}_{2} \mathrm{O}(2 \mathrm{~mL})$. Five powder samples of $\alpha-\mathrm{CD}(0.02,0.04,0.06,0.08$, and $0.10 \mathrm{mmol}$, corresponding to the molar ratios of $1: 1,1: 2,1: 3,1: 4$, and $1: 5$ of $\mathrm{KAuBr}_{4}$ to $\alpha$-CD) were added directly into the aqueous solutions of $\mathrm{KAuBr}_{4}$. The five resulting mixtures were thoroughly mixed in $4 \mathrm{~mL}$ vials. The 1:1 mixture became clear in $10 \mathrm{sec}$ and turned milky after $1 \mathrm{~h}$, while the 1:2 mixture became clear for about 1 min and then gradually turned milky. By contrast, the 
1:3, 1:4, and 1:5 mixtures became milky in $10 \mathrm{sec}$. These mixtures were then immersed into a water bath at $20{ }^{\circ} \mathrm{C}$ for $10 \mathrm{~h}$. The mixtures, which consist of pale-brown suspensions, were filtered rapidly with a Buchner funnel under vacuum. The co-precipitation yields of $\boldsymbol{\alpha} \cdot \mathbf{K} \cdot \mathbf{B r}$ were obtained indirectly by analyzing the concentrations of $\left[\mathrm{AuBr}_{4}\right]^{-}$remaining in the filtrates with UV-Vis spectrophotometry based on the absorbance of $\left[\mathrm{AuBr}_{4}\right]^{-}$at $\lambda_{\max }=\sim 380 \mathrm{~nm}$.

\section{G. ${ }^{1} \mathrm{H}$ and 2D DOSY NMR Spectroscopies}

${ }^{1} \mathrm{H}$ NMR Titrations were carried out (Figure S6) at a range of molar ratios of $\mathrm{KAuBr}_{4}$ to $\alpha-\mathrm{CD}$ from $0: 1$ to $3.55: 1$ by adding small volumes of a concentrated solution $(41.80 \mathrm{mM})$ of $\mathrm{KAuBr}_{4}$ in $\mathrm{D}_{2} \mathrm{O}$ into a solution $(1.18 \mathrm{mM})$ of $\alpha-\mathrm{CD}$ in $\mathrm{D}_{2} \mathrm{O}$. Variable-temperature (VT) ${ }^{1} \mathrm{H}$ NMR spectra (Figure S7) of a saturated solution $\left(2.20 \mathrm{mM}\right.$ at $\left.20^{\circ} \mathrm{C}\right)$ of $\boldsymbol{\alpha} \cdot \mathbf{K} \cdot \mathbf{B r}$ were recorded over a range of temperatures from 5 to $95{ }^{\circ} \mathrm{C}$ in order to investigate the dynamics of formation of $\boldsymbol{\alpha} \cdot \mathbf{K} \cdot \mathbf{B r}$. For comparison, VT ${ }^{1} \mathrm{H}$ NMR spectra (Figure S8) of a solution of $\alpha-\mathrm{CD}$ at the same concentration were recorded over a range of temperatures from 5 to $25^{\circ} \mathrm{C}$. The chemical shifts of the reference HDO at different temperature were calibrated ${ }^{\mathrm{S3}}$ based on the equation: $\delta=5.060-0.0122 T+$ $\left(2.11 \times 10^{-5}\right) T^{2}$, wherein $T$ is the temperature in ${ }^{\circ} \mathrm{C} .2 \mathrm{D}$ DOSY NMR Spectra (Figure S9) of a saturated solution $\left(2.20 \mathrm{mM}\right.$ at $\left.20{ }^{\circ} \mathrm{C}\right)$ of $\boldsymbol{\alpha} \cdot \mathbf{K} \cdot \mathbf{B r}$ and a solution of $\alpha$-CD at the same concentration were recorded at room temperature in order to investigate the formation mechanism of $\boldsymbol{\alpha} \cdot \mathbf{K} \cdot \mathbf{B r}$ in $\mathrm{D}_{2} \mathrm{O}$. 


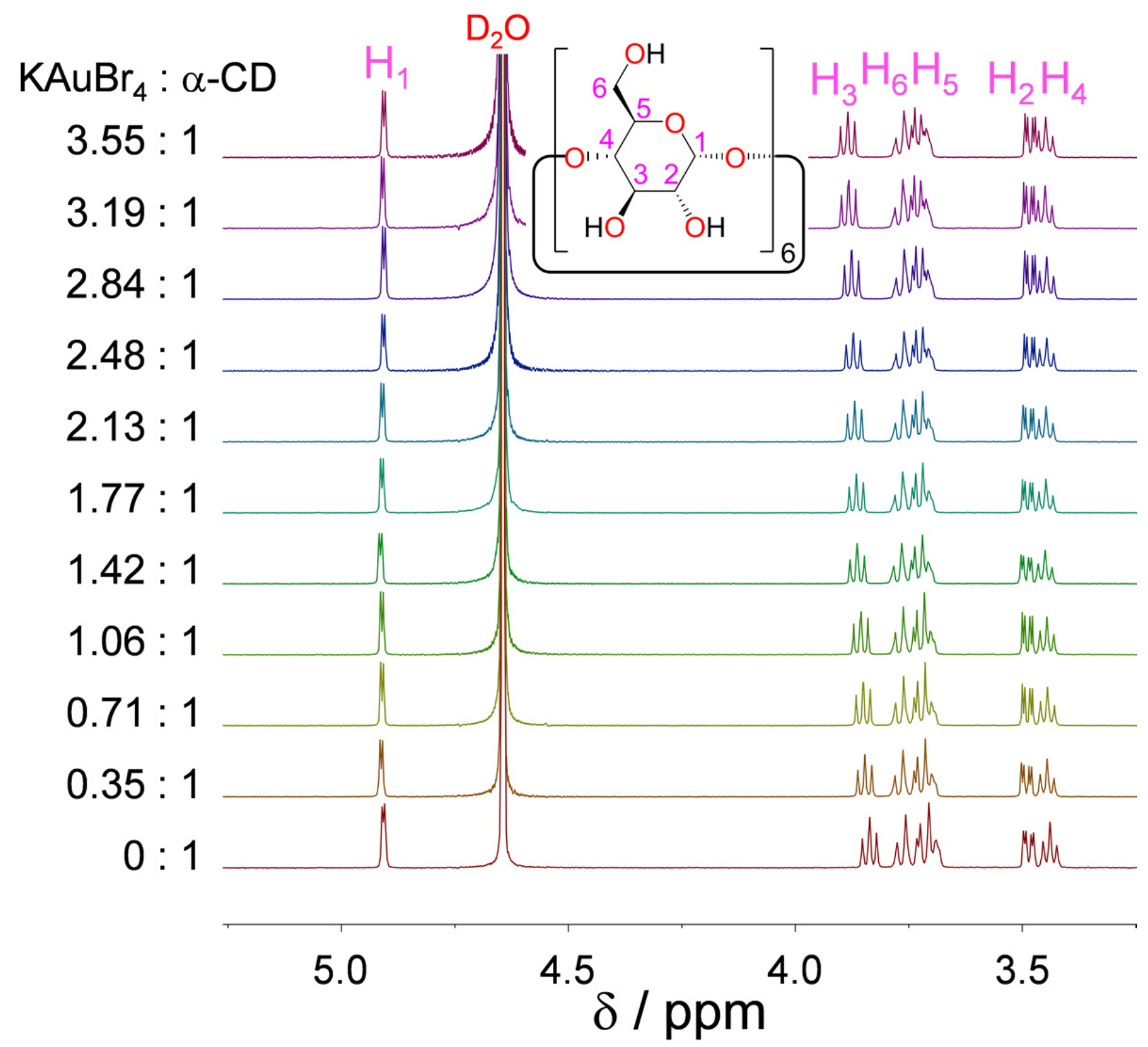

Figure S6. ${ }^{1} \mathrm{H}$ NMR Spectra $\left(600 \mathrm{MHz}, \mathrm{D}_{2} \mathrm{O}, 298 \mathrm{~K}\right)$ of mixtures of $\mathrm{KAuBr}_{4}$ and $\alpha-\mathrm{CD}$ at a range of molar ratios of $\mathrm{KAuBr}_{4}$ to $\alpha$-CD from $0: 1$ to $3.55: 1$ prepared by adding small volumes of a concentrated solution $(41.8 \mathrm{mM})$ of $\mathrm{KAuBr}_{4}$ in $\mathrm{D}_{2} \mathrm{O}$ into a solution $(1.178 \mathrm{mM})$ of $\alpha$-CD in $\mathrm{D}_{2} \mathrm{O}$. 


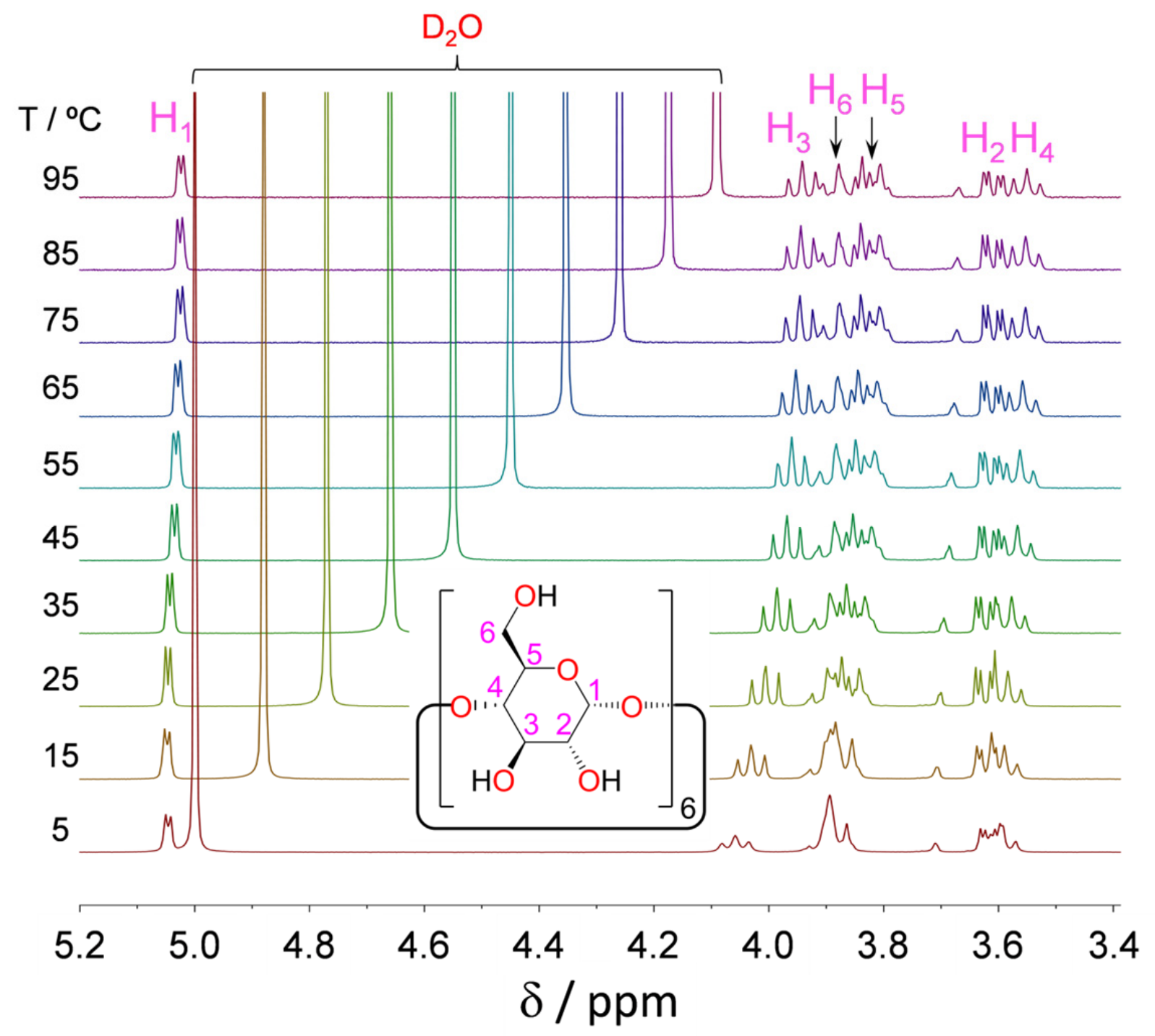

Figure S7. Variable-temperature ${ }^{1} \mathrm{H}$ NMR spectra $\left(400 \mathrm{MHz}, \mathrm{D}_{2} \mathrm{O}\right)$ of a saturated solution $(2.20$ $\mathrm{mM}, 20{ }^{\circ} \mathrm{C}$ ) of $\boldsymbol{\alpha} \cdot \mathbf{K} \cdot \mathbf{B r}$ in the range of temperatures from 5 to $95^{\circ} \mathrm{C}$. The chemical shifts of the reference $\mathrm{HDO}$ at different temperature were calibrated $^{\mathrm{S} 3}$ based on the equation: $\delta=5.060-$ $0.0122 T+\left(2.11 \times 10^{-5}\right) T^{2}$, wherein $T$ is the temperature in ${ }^{\circ} \mathrm{C}$. 


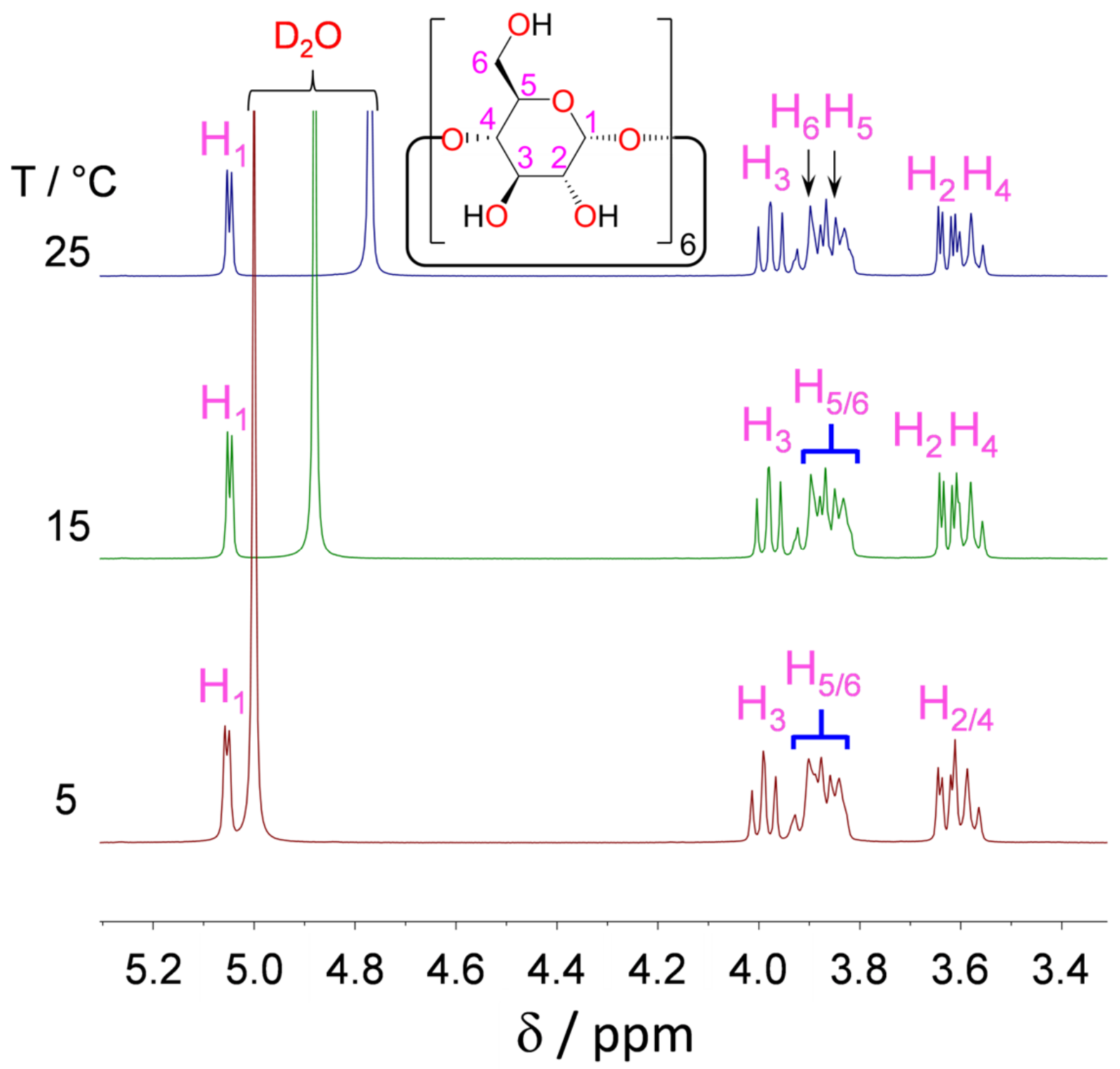

Figure S8. Variable-temperature ${ }^{1} \mathrm{H}$ NMR spectra $\left(400 \mathrm{MHz}, \mathrm{D}_{2} \mathrm{O}\right)$ of $\alpha-\mathrm{CD}$ in the range of temperatures from 5 to $25^{\circ} \mathrm{C}$. The chemical shifts of the reference $\mathrm{HDO}$ at different temperature were calibrated ${ }^{\mathrm{S} 3}$ based on the equation: $\delta=5.060-0.0122 T+\left(2.11 \times 10^{-5}\right) T^{2}$, wherein $T$ is the temperature in ${ }^{\circ} \mathrm{C}$. 


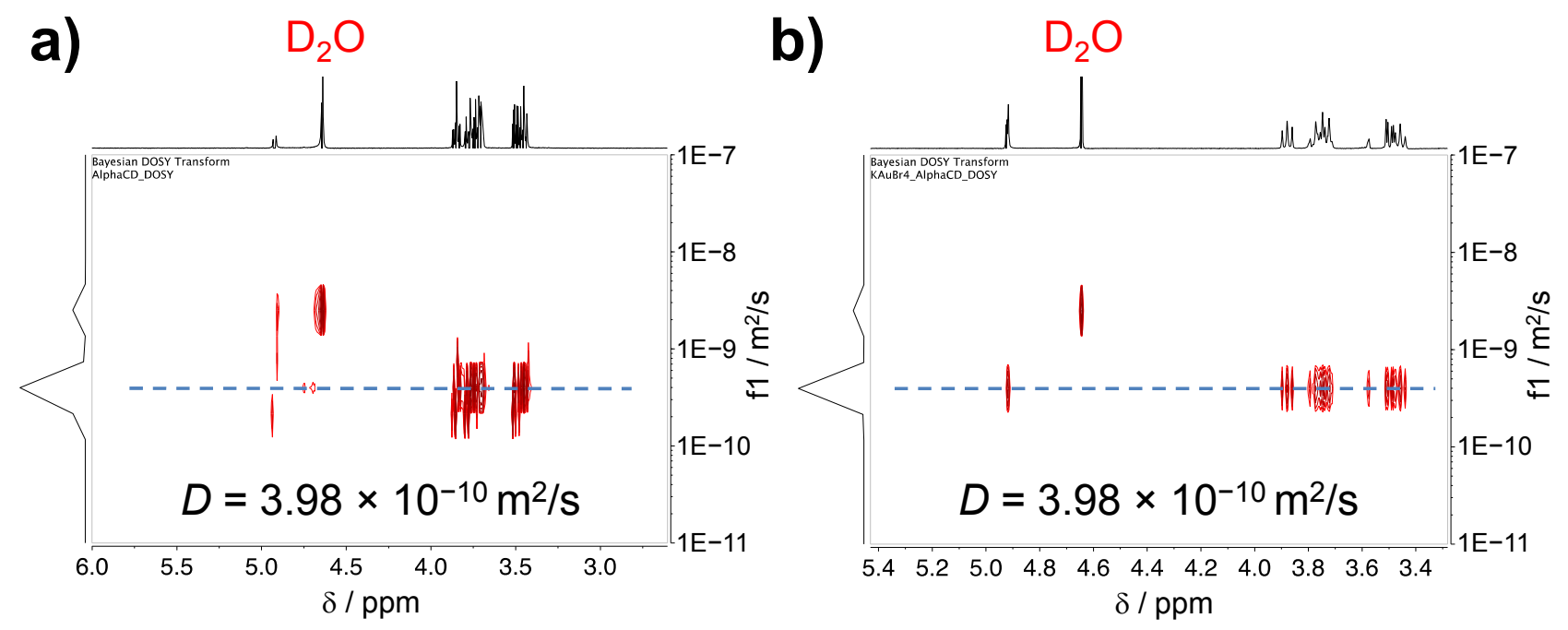

Figure S9. 2D DOSY NMR Spectra of a saturated solution $(2.20 \mathrm{mM})$ of $\boldsymbol{\alpha} \cdot \mathbf{K} \cdot \mathbf{B r}$ (a) and a solution of $\alpha-C D(b)$ at the same concentration in $\mathrm{D}_{2} \mathrm{O}$.

\section{H. References}

(S1) Sheldrick, G. Acta Crystallogr., Sect. A: Found. Crystallogr. 2008, 64, 112.

(S2) Pettersen, E. F.; Goddard, T. D.; Huang, C. C.; Couch, G. S.; Greenblatt, D. M.; Meng, E. C.; Ferrin, T. E. J. Comput. Chem. 2004, 25, 1605.

(S3) Gottlieb, H. E.; Kotlyar, V.; Nudelman, A. J. Org. Chem. 1997, 62, 7512. 